\title{
Design of High-Utilization Current-Sharing Controller for Battery-Ultracapacitor Hybrid Energy Storage System
}

\author{
Lan-Rong Dung, Zhe-Yi Lin \\ Institute of Electrical and Computer Engineering, National Chiao-Tung University, Hsinchu, Taiwan \\ Email: lennon@faculty.nctu.edu.tw
}

How to cite this paper: Dung, L.-R. and Lin, Z.-Y. (2018) Design of High-Utilization Current-Sharing Controller for BatteryUltracapacitor Hybrid Energy Storage System. Circuits and Systems, 9, 125-132. https://doi.org/10.4236/cs.2018.99013

Received: October 11, 2017

Accepted: September 10, 2018

Published: September 13, 2018

Copyright $\odot 2018$ by authors and Scientific Research Publishing Inc. This work is licensed under the Creative Commons Attribution International License (CC BY 4.0).

http://creativecommons.org/licenses/by/4.0/

Open Access

\begin{abstract}
In this paper, a new control strategy of battery-ultracapacitor hybrid energy storage system (HESS) is proposed for hybrid electric drive vehicles (HEVs). Compared to the stand, alone battery system may not be sufficient to satisfy peak demand periods during transients in HEVs, the ultracapacitor pack can supply or recover the peak power and it can be used in high C-rates. However, the problem of battery-ultracapacitor hybrid energy storage system (HESS) is how to interconnect the battery and ultracapacitor and how to control the power distribution. This paper reviewed some battery-ultracapacitor hybrid energy storage system topology and investigated the advantages and disadvantages, then proposed a new control strategy. The proposed control strategy can improve the system performance and ultracapacitor utilization, while also decreasing the battery pack size to avoid the thermal runaway problems and increase the life of the battery. The experiment results showed the proposed control strategy can improve $3 \%-4 \%$ ultracapacitor utilization.
\end{abstract}

\section{Keywords}

Ultracapacitor, DC/DC Converter, Energy Storage System, Battery

\section{Introduction}

Hybrid energy storage system (HESS) is very important of hybrid electric vehicles because environmental issue and the increasing energy cost need to be considered [1]. Then how to control the hybrid energy storage system is a very important thing. A new control strategy of battery-ultracapacitor hybrid energy storage system (HESS) is proposed for hybrid electric drive vehicles (HEVs) in this paper.

The problem of battery is that battery not be sufficient to satisfy peak de- 
mand periods during transients in HEVs, but the ultracapacitor pack can supply or recover the peak power [2] [3]. The ultracapacitor's time-constant is smaller than battery. So combining the battery and ultracapacitor is a better solution of hybrid energy storage system. Different topologies of hybrid energy sources have been studied in the literature. In this paper, we compare battery/ultra-capacitor passive topology, battery/ultra-capacitor parallel topology, and Battery/Ultra-capacitor series topology. The topology's advantages and disadvantages are shown in Section 2. Figure 1 shows the battery and ultracapacitor electrochemistry characteristics, and the control flow chart and system design flow are shown in Section 3.

\section{HESS Topology}

\subsection{Battery/Ultra-Capacitor Passive Topology}

Battery/ultra-capacitor passive topology, as shown in Figure 2, is the simplest topology of battery-ultracapacitor hybrid energy storage system. This topology directly connects battery and ultracapacitor without any controller and power converter. In this topology, the power distribution cannot be controlled, the current sharing is based on them self electrochemistry characteristics. The advantage is very easy to implement, and its disadvantage is that battery has the high frequency current ingredient.

\subsection{Battery/Ultra-Capacitor Parallel Topology}

The battery/ultra-capacitor parallel topology [4], as shown in Figure 3, is connected with two DC-DC converters in parallel. Because the DC-DC converters can control the battery current and the load voltage, the battery high frequency current problem is solved. So the topology can increase the battery cycle life and the battery bank size can decrease.

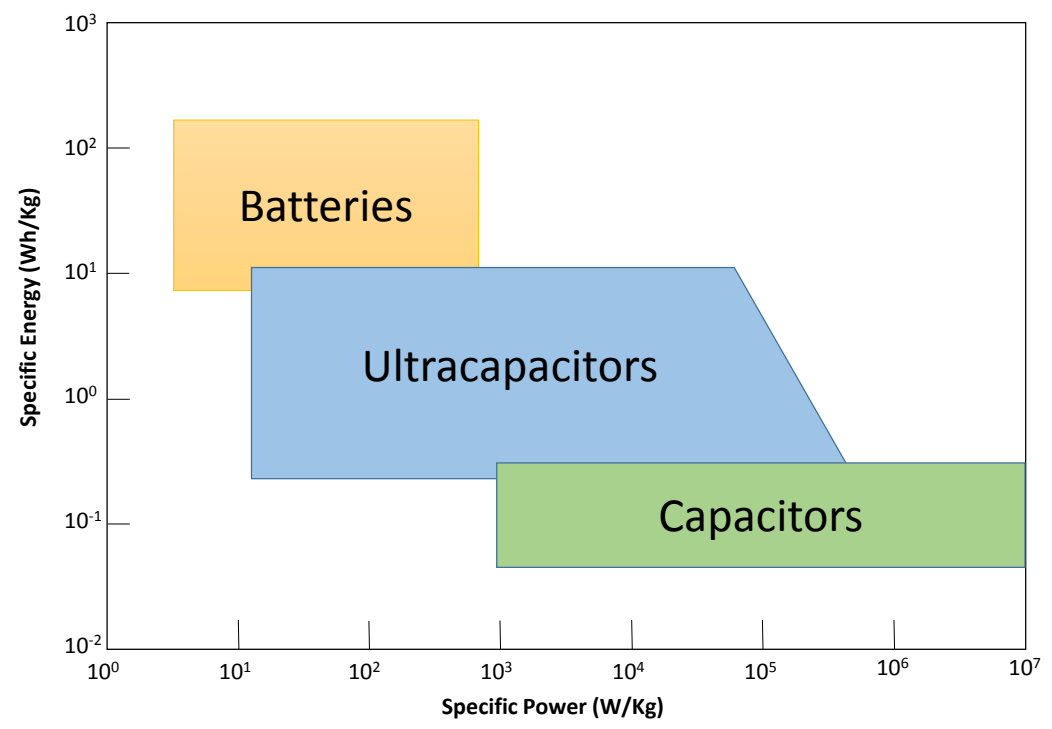

Figure 1. Electrochemistry characteristics of energy storage devices. 


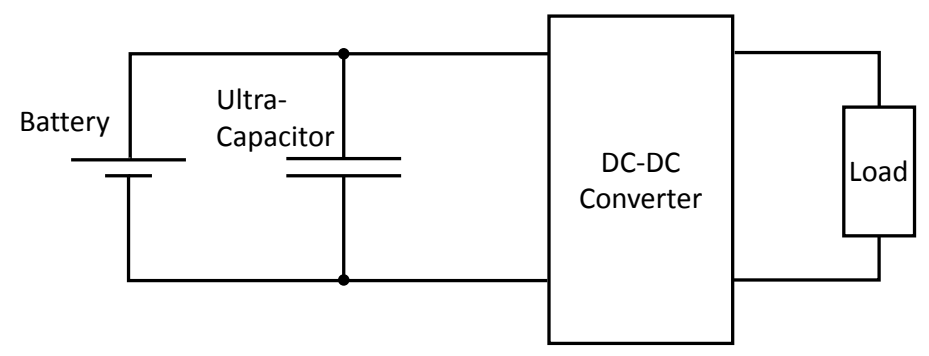

Figure 2. Battery/Ultra-capacitor passive topology.

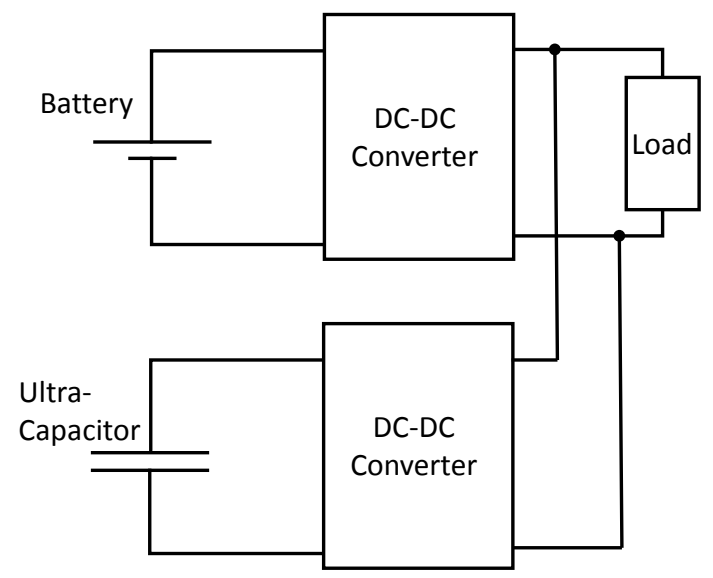

Figure 3. Battery/Ultra-capacitor parallel topology.

\subsection{Battery/Ultra-Capacitor Series Topology}

Battery/ultra-capacitor series topology [5], as shown in Figure 4, is connected with two DC-DC converters in series. The two DC-DC converters also can control the battery current and the load voltage, the battery high frequency current problem is solved. Compare to the battery/ultra-capacitor parallel topology the series topology's converter size can be smaller.

\section{Proposed Control Strategy and Design}

\subsection{The Current Control Strategy}

A new current control strategy is proposed in this paper. Because the ratio of peak power and average power in hybrid electric vehicles is 10:1 [6], battery provides the average power and ultracapacitor provide the transient power. So the battery current is controlled to the load average current with a low-pass filter. In this paper, the low-pass filter is substituted by moving average. The battery current $I_{b a t}$ is show as (1), and the ultracapacitor current $I_{U C}$ is how as (2), where $I_{L}$ is the load current and $M$ is the size of moving average window.

$$
\begin{gathered}
I_{b a t}[n]=\frac{1}{M} \sum_{i=1}^{i=M} I_{L}[n-i+1] \\
I_{U C}[n]=I_{L}[n]-I_{b a t}[n]
\end{gathered}
$$

In HESS, the ultracapacitor's voltage needs to be control. In this paper, use changing moving average window size between sampling point and sampling 


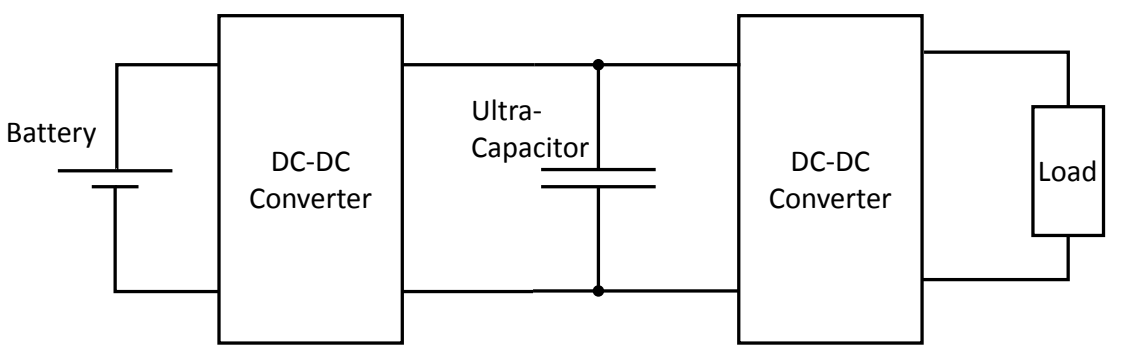

Figure 4. Battery/Ultra-capacitor series topology.

point to produce nonlinear $\mathrm{dc}$ current that can use to charge the ultracapacitor. The nonlinear dc current derivations are shown in (3) and (4).

$$
\begin{gathered}
I_{b a t}[n+1]=\frac{1}{M}\left\{I_{L}[n-M+2]+I_{L}[n-M+3]+\ldots+I_{L}[n]+I_{L}[n+1]\right\} \\
I_{b a t}^{+}[n+1]=\frac{1}{M+1}\left\{I_{L}[n-M+1]+I_{L}[n-M+2]+\ldots+I_{L}[n+1]\right\}
\end{gathered}
$$

The Equation (3) is the battery current at $(n+1)$ sampling point without changing the window size, the Equation (4) is battery current which change the window size. Comparing (3) and (4), the differential current $\operatorname{diff}^{+}[n+1]$ is shown as (5). In this paper, use the difference current to charge the ultracapacitor, and control the ultracapacitor in a range.

$$
\operatorname{diff}^{+}[n+1]=I_{b a t}^{+}[n+1]-I_{b a t}[n+1] \cong \frac{1}{M+1} \cdot I_{L}[n-M+1]
$$

The Hybrid Energy storage system is implement in digital circuit so the HESS control software flow chart is shown in Figure 5. For performance evaluation, the ultracapacitor utilization is defined in (6), where $P_{r m s, c a p}$ is the root mean square of power disspation in untracapacitor and $P_{r m s, b a t}$ is the root mean square of power disspation in battery.

$$
U_{\text {capacitor }}=\frac{P_{r m s, c a p}}{P_{r m s, c a p}+P_{r m s, b a t}}
$$

\subsection{Design of DC/DC Converter}

A small-signal transfer function for PWM DC-DC converter is needed to understand the converter performance and control. Since we have to control the input current of the converter which is also equal to the inductor current, transfer function between duty cycle and inductor current needs to be determined.

The boost converter can be modeled with a circuit averaging technique [7], as shown in Figure 6. For a CCM boost converter, the currrent through the switching transistor is shown in (7), where $(D+d)$ is the duty cycle and $I_{L}+i_{l}$ is the inductor current, and the voltage of diode is shown in (8), where $V_{O}+v_{o}$ is the output voltage.

$$
\begin{gathered}
i_{S}=(D+d)\left(I_{L}+i_{l}\right) \\
v_{D}=(D+d)\left(V_{O}+v_{o}\right)
\end{gathered}
$$




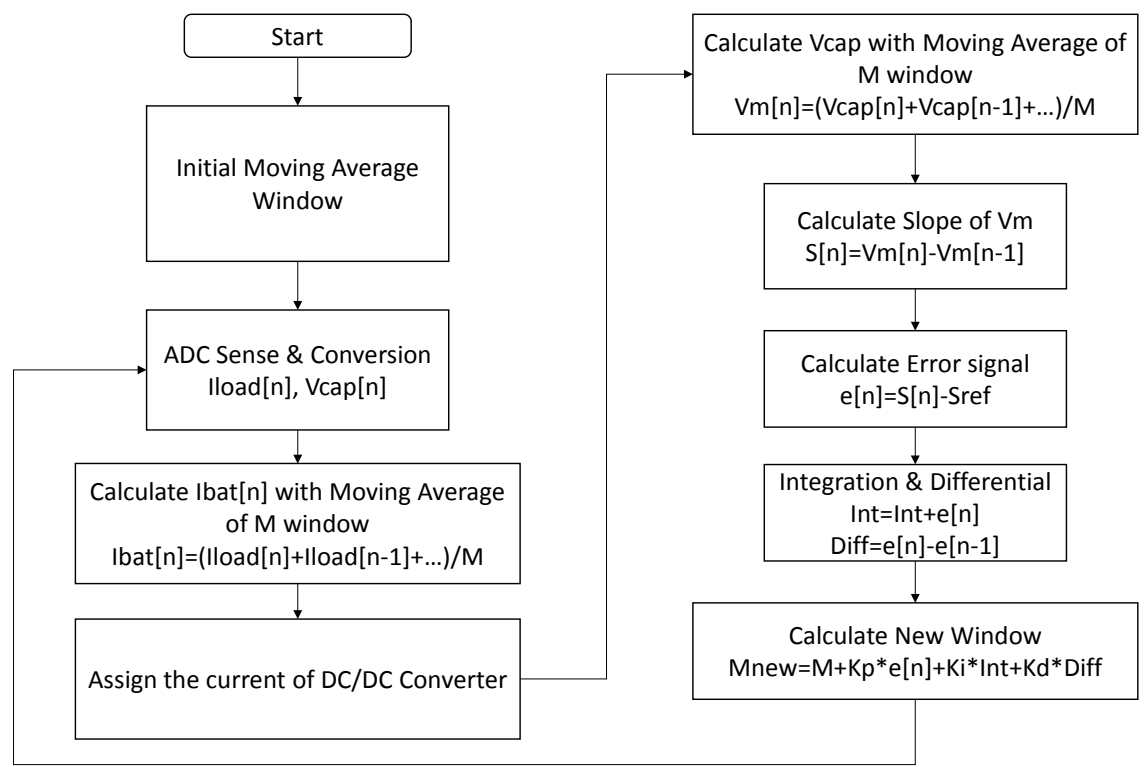

Figure 5. Flow chart of the proposed HESS current control strategy.

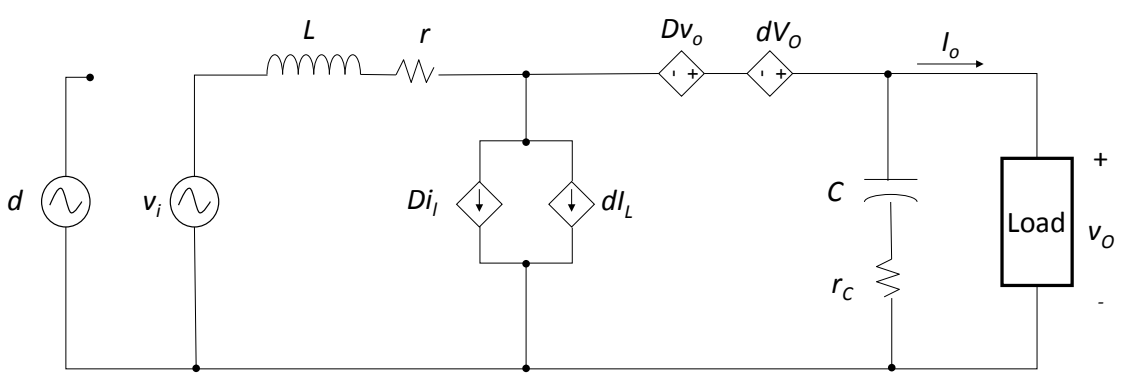

Figure 6. The small-signal model of CCM boost converter.

For $Z_{1}=s L+r, \quad Z_{2}=1 / s C+r_{c}$, and $r=r_{s}+r_{L}+D r_{D S}+(1-D) R_{F}$, we can derive the transfer function of the duty cycle to inductor current for CCM boost converter as (9).

$$
G_{i d}(s)=\frac{i_{l}(s)}{d(s)}=\frac{r_{C} I_{O}+V_{O}}{L} \frac{s+\frac{I_{O}}{C\left(r_{C} I_{O}+V_{O}\right)}}{s^{2}+\left[\frac{r+r_{C}(1-D)^{2}}{L}\right] s+\frac{(1-D)^{2}}{L C}}
$$

\section{Experimental Results}

Figure 7 shows proposed hybrid energy storage system circuit, we verify developed the system based on a DSP controller. The DSP device is Texas Instrument DSP320F2812, and we used it with its function such as 12 bit resolution ADC, high speed PWM module and high speed computation ability for type-III compensation. The PWM signals generated by the DSP controller are applied at a low-side driver to drive the MOSFET switching. The current sharing of battery and ultracapacitor algorithm is also build with DSP controller.

Figure 8 shows the physical setup of HESS system, where the part A is the 


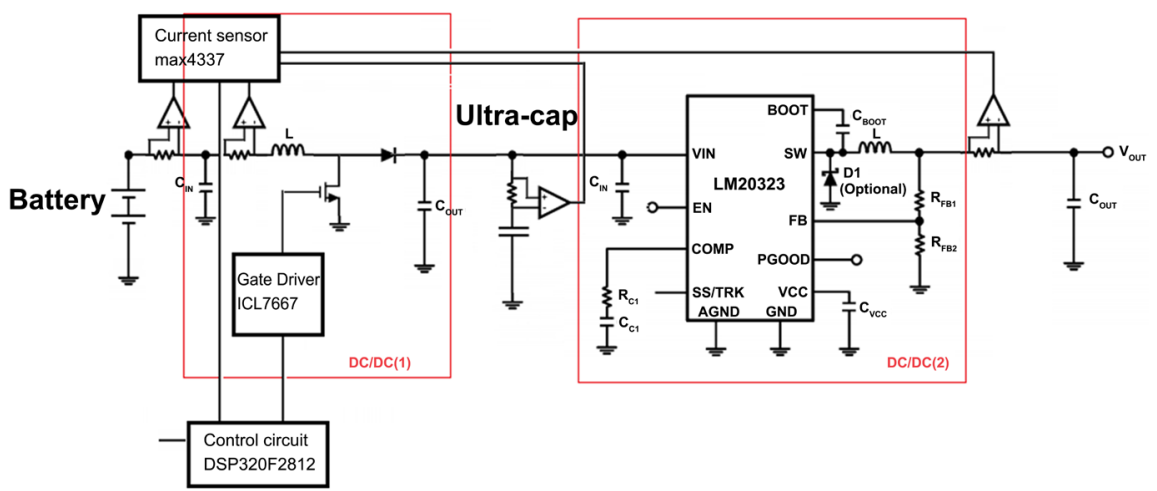

Figure 7. The circuit implementation of HESS controller.

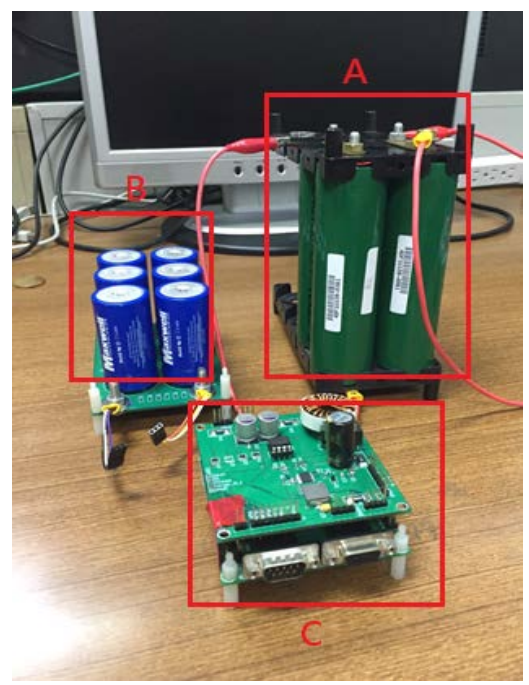

Figure 8. The experimental setup of HESS.

lithium battery module, the part B is the ultracapacitor module, and the part $\mathrm{C}$ is the control circuit module. The experimental current waveforms are shown in Figure 9 and Figure 10. Figure 9 shows the battery current and Figure 10 shows the ultracapacitor current. We can see the battery current change is flat and the proposed control strategy can improve 3\% - 4\% ultracapacitor utilization.

\section{Conclusion}

In this paper, a new control strategy of battery-ultracapacitor hybrid energy storage system (HESS) is proposed for hybrid electric drive vehicles (HEVs). Compared to the stand alone battery system may not be sufficient to satisfy peak demand periods during transients in HEVs, the ultracapacitor pack can supply or recover the peak power and it can be used in high C-rates. However, the problem of battery-ultracapacitor hybrid energy storage system (HESS) is how to interconnect the battery and ultracapacitor and how to control the power distribution. This thesis reviews some battery-ultracapacitor hybrid energy storage system topology and investigates the advantages and disadvantages, then proposes a 


\section{Battery Current}

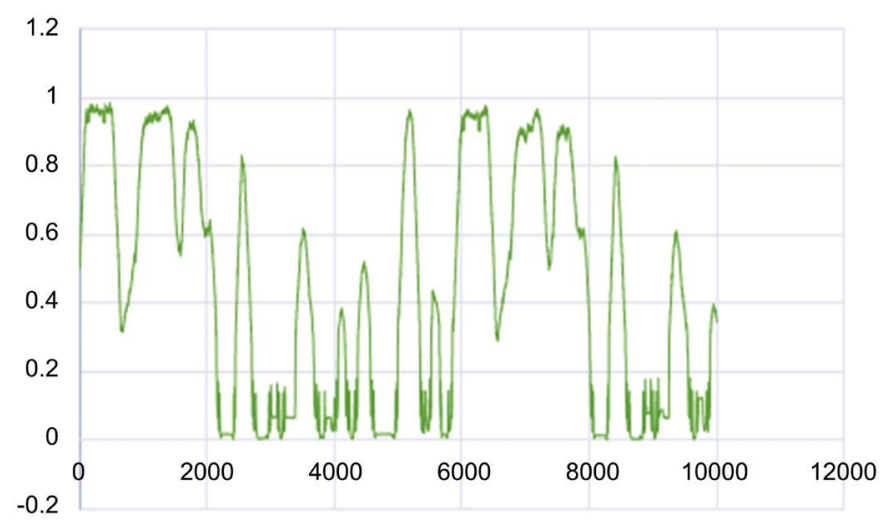

Figure 9. The battery current waveform of HESS.

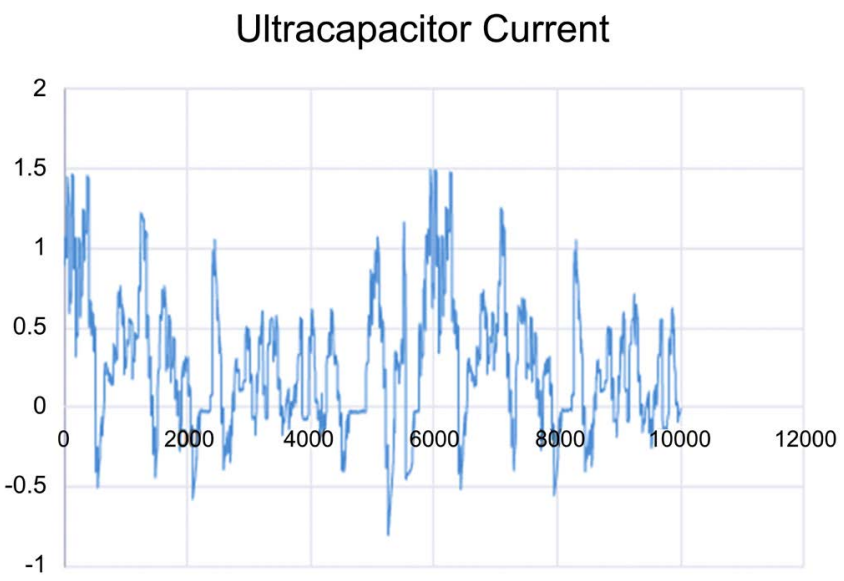

Figure 10. The ultracapacitor current waveform of HESS.

new control strategy. The proposed control strategy can improve the system performance and ultracapacitor utilization, while also decreasing the battery pack size to avoid the thermal runaway problems and increase the life of the battery. The experiment results show the proposed control strategy can improve $14 \%$ ultracapacitor utilization.

\section{Acknowledgements}

The authors would like to thank the editor and the referee for their comments. This work was supported in part by the Ministry of Science and Technology, Taiwan, under Grant No. 106-2221-E-009-014.

\section{References}

[1] Duryea, S., Islam, S. and Lawrance, W. (2001) A Battery Management System for Stand-Alone Photovoltaic Energy Systems. IEEE Industry Applications Magazine, 7, 67-72. https://doi.org/10.1109/2943.922452

[2] Kang, K., Meng, Y.S., Breger, J., Grey, C.P. and Ceder, G. (2006) Electrodes with High Power and High Capacity for Rechargeable Lithium Batteries. Science, 311, 
977-980. https://doi.org/10.1126/science.1122152

[3] Hsieh, Y.C., Moo, C.S., Tsai, T.J. and Ng, K.S. (2011) High-Frequency Discharging Characteristics of LiFePO4 Battery. IEEE Conference on Industrial Electronics and Applications, Beijing, 21-23 June 2011, 953-957.

[4] Cao, J. and Emadi, A. (2012) A New Battery/Ultra-Capacitor Hybrid Energy Storage System for Electric, Hybrid and Plug-In Hybrid Electric Vehicles. IEEE Transactions on Power Electronics, 27, 122-132.

https://doi.org/10.1109/TPEL.2011.2151206

[5] Onar, O. and Khaligh, A. (2008) Dynamic Modeling and Control of a Cascaded Active Battery/Ultra-Capacitor Based Vehicular Power System. IEEE Vehicle Power and Propulsion Conference, Harbin China, 3-5 September 2008.

[6] Zhang, Y., Jiang, Z. and Yu, X. (2008) Control Strategies for Battery/Supercapacitor Hybrid Energy Storage Systems. IEEE Energy 2030 Conference, Atlanta, GA, 17-18 November 2008. https://doi.org/10.1109/ENERGY.2008.4781031

[7] Bryant, B. and Kazimierczuk, M.K. (2004) Small-Signal Duty Cycle to Inductor Current Transfer Function for Boost PWM DC-DC Converter in Continuous Conduction Mode. 2004 IEEE International Symposium on Circuits and Systems, Vancouver, BC, 23-26 May 2004, 856-859. 